\title{
How Cognitive Science Has Influenced the Applied Science of HCI "The evolution that envies the revolution"
}

\author{
Thomas Virgona, $\mathrm{PhD}$.
}

\begin{abstract}
Science research contributions to applied science have been staggering, to say the least, over the last 25 years. Almost every computer related field or discipline has made significant strides that have impacted every day life. The field of human-computer interaction has made such minor break-throughs, one could argue if it is really an independent field of study, or simply a subset of analysis and design? Does the research belong in the field of psychology, as a result of the strong dependency on cognitive thinking? The study of HCI allows us to explain the overall decisions that individuals make when using technologies.Although a wealth of studies already exist on modeling mental processes, epistemological and methodological, issues in the context of developing user interfaces have remained untouched. (Stary, Chris, Peschl, Mark F 1998). Cognition is the subject of change. Has Cognitive Science influenced the Applied Science Of HCI? Yes. Has Cognitive Science impacted the Applied Science Of HCI? No.
\end{abstract}

\section{Introduction}

MRI's, the Mars rover landing, the Internet. Science research contributions to applied science have been staggering, to say the least, over the last 25 years. Almost every computer related field or discipline has made significant strides that have impacted every day life. The field of human-computer interaction has made such minor break-throughs, one could argue if it is really an independent field of study, or simply a subset of analysis and design? Does the research belong in the field of psychology, as a result of the strong dependency on cognitive thinking?

Since the 1960s, the rapid growth of information systems has led to the wide development of research on human-computer interaction (HCI) which aims at the designing of human-computer interfaces presenting ergonomic properties, such as friendliness, usability, transparency, etc (Hoc 2000). Rather than focusing solely on characteristics of individual technologies, or psychological and social issues, the study of HCI allows us to explain the overall decisions that individuals make when using technologies.

A sampling of research studies will serve as the basis for the statement above. Using Fipps law as an example, research determined humans can find a larger object faster on a computer screen than smaller object. Using up to four characters was the best single domain length is hardly front-page news (Rau, Pei-Luen P., Salvendy G., 2001). These examples of HCI studies, although interesting, are not "fit-for-design-purpose" (Long, J. 1996). As a result of the quickening tempo of technology change and the expansion of technological possibilities, there is an enormous need for the development of techniques that gain insight into the systems development (Woods, David, Dekker, Sidney 2000).

Has Cognitive Science influenced the Applied Science Of HCI? Yes. Has Cognitive Science impacted the Applied Science Of HCI? No. Although a wealth of studies already exist on modeling mental processes, epistemological and methodological, issues in the context of developing user interfaces have remained untouched. (Stary, Chris, Peschl, Mark F 1998). Cognition is the subject of change. It is argued that one may be facing yet another change, the notion of extended cognition, which refers to the way in which people use technological and cognitive artifacts to improve their ability to control a situation. Since the "information society" both increases the number of artifacts one can use, and raises the demands to being in control, the notion of extended cognition can provide a way to both identify the impending problems and outline the solutions (Hollnagel, Erik. 2001).

To initiate the discussion of influence on human computer interaction (HCI) to applied science, one can start the discussion with the goals of HCI to determine the impact of the contributions. A generally accepted definition states that the main goal of $\mathrm{HCI}$ is to advance the design, implementation, and use of interactive computing systems by human beings. Since the primary use of computers is as tools for acting on and for observing the information world, the role of HCI is to understand the following (Pollitzer E., Edmonds E 1996):

- How do our interactions with computing systems affect our representations of the objects that we manipulate?

- How does interactions design influence our senses and our actions?

- How does using computers to perform tasks transforms our notions of the relationships that exist in the world around us? 
Many computer users have trouble learning and remembering information presented on a computer screen (Chalmers, P.A. 2003). Based on cognitive theories, part of the reason for lack of retention is believed to be the user's inability to form a mental picture, or schema, of the information presented via a computer screen. In order to form a schema, users need to be able to understand where newly acquired knowledge fits into "the big picture". However, computers and the information on them are so infinite, users may have trouble thinking in terms of a big picture. It is proposed that these problems of the inability to form a schema and disorientation with the human-computer interface are worth researching, not only for better retention, but also for increased satisfaction among users.

\section{Key Definitions}

Before a discussion of the influence or impact on applied science by Cognitive Science can start, one must define some operational terms. Below is a list of some relevant terms discussed in recent research studies.

\begin{tabular}{|c|c|c|}
\hline Term & Definition Source & Definition \\
\hline Affordance & Hartson, 2003 & $\begin{array}{l}\text { There are four complementary types of affordance in the context of interaction } \\
\text { design and evaluation: cognitive affordance, physical affordance, sensory } \\
\text { affordance, and functional affordance. The terms cognitive affordance (Norman's } \\
\text { perceived affordance) and physical affordance (Norman's real affordance) refer to } \\
\text { parallel and equally important usability concepts for interaction design, to which } \\
\text { sensory affordance plays a supporting role. The concept of physical affordance } \\
\text { carries a mandatory component of utility or purposeful action (functional } \\
\text { affordance). Finally, we provide guidelines to help designers think about how } \\
\text { these four kinds of affordance work together naturally in contextualized HCI } \\
\text { design or evaluation. }\end{array}$ \\
\hline Agent & $\begin{array}{l}\text { Dobbyn, C, Stuart, S. } \\
2003\end{array}$ & $\begin{array}{l}\text { In cognitive science agents are seen as embodied and interactively situated in } \\
\text { worlds. }\end{array}$ \\
\hline Artificial emotion & $\begin{array}{l}\text { Botelho, Luis Miguel, } \\
\text { Coelho, Helder } 2001 .\end{array}$ & $\begin{array}{l}\text { A preliminary definition and theory of artificial emotion, viewed as a sequential } \\
\text { process comprising the appraisal of the agent global state, the generation of an } \\
\text { emotion-signal, and an emotion-response. This theory distinguishes cognitive } \\
\text { from affective appraisal on an architecture-grounded basis. Affective appraisal is } \\
\text { performed by the affective component of the architecture; cognitive appraisal is } \\
\text { performed by its cognitive component. }\end{array}$ \\
\hline $\begin{array}{l}\text { Cognitive } \\
\text { informatics. }\end{array}$ & Wang Y. 2003. & $\begin{array}{l}\text { Cognitive informatics is the transdisciplinary study of cognitive and information } \\
\text { sciences that investigates into the internal information processing mechanisms and } \\
\text { processes of the natural intelligence - human brains and minds. Cognitive } \\
\text { informatics is a branch of information and computer science that studies } \\
\text { computing by cognitive methodologies and studies cognitive science by } \\
\text { informatics and computing theories. Cognitive informatics is a cutting-edge and } \\
\text { profound interdisciplinary research area that tackles the fundamental problems of } \\
\text { modern informatics, computation, software engineering, artificial intelligence, } \\
\text { cognitive science, neuropsychology, and life sciences. Almost all of the hard } \\
\text { problems yet to be solved in the above areas share a common root in the } \\
\text { understanding of mechanisms of natural intelligence and cognitive processes of } \\
\text { the brain. Cognitive informatics is perceived as a new frontier that explores the } \\
\text { internal information processing mechanisms of the brain, and their engineering } \\
\text { applications in computing and the information technology industry. }\end{array}$ \\
\hline
\end{tabular}

\section{Methodology}

Selecting a methodology to define the contribution from cognitive science to the applied science of $\mathrm{HCI}$ can be derived from previous studies. Since this research will be required to perform a database search, the researcher is keenly aware of keyword search issues, but natural language searches have been successful used in the past (Garfield, Pudovkin and Istomin 2003). Scope is a serious concern when addressing a large topic during a shortened time frame. Rather than aiming for total inclusiveness, the more limited objective of mapping highly cited literature over a broad range of disciplines is a more realistic goal in the short run (Small 1999). For this reason, the specific aspects of HCI reviewed will be the area of cognitive science. The purpose of concentrating on a well-defined area is to make the subject manageable (Clanchy 1979). As stated by Small (2003), the goal is to complete a project before one retires.

In building the research methodology, the starting point will be to construct a bibliography from a database based on a search by keywords, cited authors, cited papers or books, or by a source journal (Garfield, Pudovkin and Istomin 2003). Using this as a basis for the research, the methodology is as follows:

Table 1 - Research Methodology 


\begin{tabular}{|c|c|c|}
\hline Task & Description & Result \\
\hline \multirow[t]{5}{*}{1} & Tool Identification & \\
\hline & Internet Browser & $\begin{array}{l}\text { Microsoft Internet Explorer using a corporate (Citigroup) } \\
\text { proxy server. }\end{array}$ \\
\hline & Data Collection & Microsoft Excel \\
\hline & Word Processing & Microsoft Word \\
\hline & Citation Database & $\begin{array}{l}\text { Emerald will be the primary search tool, selected for } \\
\text { breadth of journals. It is known that Ingenta is a viable } \\
\text { scholarly data repository, and in the event that Emerald is } \\
\text { unavailable during he research period, Ingenta will be } \\
\text { used. The purpose of concentrating on one topic is to } \\
\text { make the subject manageable. }\end{array}$ \\
\hline \multirow[t]{3}{*}{2} & Search Parameters & \\
\hline & Identification of search terms & $\begin{array}{l}\text { - Cognitive Science } \\
\text { - Applied Science Of Human-Computer Interaction } \\
\text { Ingenta and Emerald both allow for single/multiple term } \\
\text { entry, which searches keywords, titles, authors, etc. }\end{array}$ \\
\hline & $\begin{array}{l}\text { Years: In our study, we use an } 8 \text {-year cluster } \\
\text { of documents to examine the development of } \\
\text { the field. }\end{array}$ & $\begin{array}{l}\text { Both Ingenta and Emerald allow for date selection. The } \\
\text { purpose of concentrating on a well-defined period is to } \\
\text { make the subject manageable. An eight-year window } \\
\text { allows for recent research and will show trends and } \\
\text { patterns. }\end{array}$ \\
\hline 3 & Execution of citation database searches & Conducted during month of March 2004. \\
\hline 4 & Retrieval of relevant works & $\begin{array}{l}\text { Every returned item was analyzed for any relevance to } \\
\text { the search term. }\end{array}$ \\
\hline 5 & Date Analysis & $\begin{array}{l}\text { Each article and year will be entered on a unique row in } \\
\text { the data collection spreadsheet. }\end{array}$ \\
\hline
\end{tabular}

Table 2 - Research Risk Identification

\begin{tabular}{|l|l|l|}
\hline Description & Risk Mitigation \\
\hline Indexing issues & $\begin{array}{l}\text { Search terms may not retrieve the } \\
\text { desired article. Interdisciplinary and } \\
\text { cross over field are frequently } \\
\text { encountered and the keyword can } \\
\text { occasionally defy its disciplinary } \\
\text { origins (Small 1999). }\end{array}$ & $\begin{array}{l}\text { The number of articles not catalogued under these } \\
\text { terms, but are nevertheless relevant, are expected } \\
\text { to be minimal. }\end{array}$ \\
\hline Retrieval of relevant works & $\begin{array}{l}\text { A retrieved work may be omitted. } \\
\text { Retrieval of relevant works }\end{array}$ & $\begin{array}{l}\text { A liberal' selection criteria will be used, } \\
\text { including any work which is relevent to the } \\
\text { selected terms. }\end{array}$ \\
\hline $\begin{array}{l}\text { Scholarly notabase } \\
\text { available }\end{array}$ & $\begin{array}{l}\text { Unable to perform retrieval of article may not be available. } \\
\text { documentation. }\end{array}$ & $\begin{array}{l}\text { In the event the article is not physically accessible, } \\
\text { the on-line abstract will be used. }\end{array}$ \\
$\begin{array}{l}\text { In the event Emerald Insight is not available on a } \\
\text { day that retrieval is scheduled to be performed, } \\
\text { Ingenta will be used as a substitute scholarly } \\
\text { search engine. }\end{array}$ \\
\hline
\end{tabular}

\section{Research Findings}

In general, cognitive science as it relates to applied HCI has a vast body of research. Throughout the HCI field, the research shoes humans as adaptive decision makers, a vital concept for a deep understanding of HCI and classical cognitive conception (Payne, Stephen J., Howes, Andrew, Reader, William R. 2001). With the rapid progress of information technology, the work environments that cognitive HCI research should deal with are changing (Yoon, Wan Chul 2001). From an ontological perspective, the contributions can be set into the following categories: financial, education, and new technology.

At a high level, the current HCI vision in research can be described as (Roco, M.C. 2002):

(a) The broad potential of converging technologies;

(b) Expanding human cognition and communication;

(c) Improving human health and physical capabilities;

(d) Enhancing group and societal outcomes;

(e) National security, and

(f) Unifying science and education.

\section{Finance and Business}

When discussing human computer interaction, pragmatism tells us that finances will play a prominent role in the research due to the costliness of hardware, software and human resources. Classic economic supply and demand curves allow us to make both qualitative and quantitative predictions about technological adoption. Without necessarily understanding all the local decision criteria used by any individual, we can make robust 
predictions about how an organization as a whole will interact (Coiera, E. 2003). The cost justification process is a major concern for those organizations considering the development of an information technology information systems infrastructure, which in turn is putting the competitive advantage of many companies at risk. The reason for this centers around management's inability to evaluate the holistic implication of adopting new technology, both in terms of the benefit and finances (Irani Z., Sharif A., Love P.E.D., Kahraman C. 2002).

Economically, a digital divide exists. As the use of information technology (IT) has grown, the demand for workers with technical skills has also increased dramatically. Yet, the supply of these workers has not kept pace. One reason for this supply-demand disparity is the insufficient number of women and minorities entering engineering and science-related fields. This is disturbing since these two groups are the fastest growing segment of the US population. Empirical research is needed to investigate why these two important population segments are not active participants in the digital revolution. Research has suggested that personality composition (particularly motivation), self esteem, learning styles, and cognitive thinking-influences a person's academic performance and the decision to pursue IT education and careers. The technological sophistication of a person's environment also influences these variables and moderates the relationship between personality and IT career choices (Wilbon, A.D 2003).

Advances in computational technology based on emerging work in decision theory, information technology, and cognitive science will allow for the use of computational models in more expansive "advisory" roles to decision makers of all types. To what degree can public sector decision makers use computational models to support or advise decision-making? Computer-based decision support models have yet to provide credible economic benefits (Saunders-Newton, D., Scott, H. 2001).

\section{Education}

In terms of focus, HCI cognitive research made significant contributions to the area of education. Frequently technology educators tout the effectiveness of their programs based on anecdotal evidence gathered from their classroom experiences on how their instructional methods empower students to learn (De Miranda 2004). Although technology education originated without any meaningful input from cognitive science research, it appears that technology education instruction methods are remarkably constant with findings from cognitive science that define quality instruction. The role of the cognitive research findings on instruction could inform a long over-due theoretical grounding of instruction in technology education (De Miranda 2004).

How can new technology transform scholarly practices? Studies were global and local, focusing primarily on improving the education process itself. And obviously, the Internet was a central theme, described as a social and cognitive space. Though a computer and keyboard are usually the interface of the Internet experience, there are different ways in which users can explore the Internet, present themselves, and communicate using it. Underlying all of the research is the basic concept of this new environment; an environment we can view as having a cognitive component (hyperspace) and a social component (cyberspace) (Boechler, Patricia M. 2001). The handling of information is linked to the activation of psychosocial relationships in which cognitions are elaborated. This happens inside a rather special kind of container Cyberspace - which tends to rarefy the structural and process features of communication (Riva, Giuseppe 2001). Making the internet a pedagogical tool to leverage the cognitive skills of the pupils, and to be an enabler to reengineering the productive processes within the schools, and the need of a new educational paradigm for the schools and how the Internet can be useful in defining it (Joia, LuizAntoni 1997).

Starting with educational basics - reading and math, what, if any, is the impact of HCI on these areas? Six study and test sessions over 10 months examined test scores and retrieval responses for learning material presented via these two media, paper and CRT. Correct scores did not differ suggesting that close matching of paper and screen material can eliminate any decrement in reading speed or accuracy from screens (Garland, Kate, Noyes, Jan. 2003). In the area of mathematics, a 'technology-neutral' mathematics question which was attempted by approximately equal numbers of students using a CRT and traditional pencil-and-paper approaches revealed that students who used the latter approach were more successful than their CRT counterparts (Lindsay 1999). It was concluded in the study that every effort should be made to design questions that cater for both approaches, while being fully aware of the cognitive hurdles faced by students when utilizing software.

What can be derived from computer software used to solve mathematics problems? A study of a mathematics problem solving activity about distance, rate, time relationships in a computer software environment designed to support understanding of functional relationships among these variables (e.g., distance $=$ rate $\times$ time; time $=$ distance/rate) used graphical representations of the results of simulations. Ten adolescentaged students used the software to solve two distance, rate, time problems, and provided think-aloud protocols. When students had a weak understanding, verbal assistance was still necessary to make accurate assessments about what was and was not understood (Goldman, S.R., Zech L.K., Biswas G., Noser, T. 1999). A new approach to the cognitive science of mathematics, based on the notion of 'embodied cognition' assumes that 
mathematics cannot be considered as an isolated event or activity. Accordingly, mathematical concepts derive from the cognitive activities of subjects and are highly influenced by the body structure (Bazzini L 2001).

From educational design perspective, technological linguistic challenges abound (Norman, E. 1998). Most evident is that students need additional training in the area of HCI. All levels of students need exposure to non-routine problems that illustrate the effective use of technology in their education. Students will learn that technology can be an effective tool for investigating problems, but the burden of providing convincing arguments and proofs of their conjectures rests squarely on the students (Grassl, Richard M., Mingus Tabitha T. Y. 2002).

\section{New technology}

By definition, Human-Computer Interaction delves into cutting edge technology. The research into HCI is no exception. For headline grabbing research, the use of "robots as cognitive tools" and what has been and can potentially be learned about human cognition by employing robots as cognitive tools is astonishing (Pfeifer, R. 2002). A robotic experiment was presented in which mobile robots develop a symbolic structure from scratch by engaging in a series of language games (Vogt 2002). In this experiment it is shown that robots can develop a symbolic structure with which they can communicate the names of a few objects with a remarkable degree of success. It is further shown that, although the signs may be interpreted differently on different occasions, the objects are usually named with only one form. By any measurement, this research would be considered significant. But has it contributed to HCI application in a pragmatic way?

Genuine HCI contributions are tangible in the field of improving the quality of life when dealing with people with disabilities. A prototype e-mail system was developed for cognitively disabled users, with four different interfaces: free format, idea prompt, form fill and menu driven (Sutcliffe A., Fickas S., Ehlhardt, M.M.S.A. 2003). Also, a virtual reality-based driving-assessment system (VR-DAS) for the impaired permits the development of real driving situations that can provide objective and quantifiable measures of driving behaviors, allowing for the creation of realistic and interactive driving scenarios at varying levels of challenge and complexity. When coupled with the features offered through a headmounted display (HMD), the VR-DAS may allow drivers to experience the sense of real-life driving, resulting in behavior and responsiveness that may be more predictive of actual driving ability (Schultheis, Mourant 2001).

Other studies provided additional grounded theory and philosophy for the discipline. For example, interpreting facial expressions with the use of new technologies was studied in 2000 (Lisetti, C.L., Schiano, D.J. 2000). The research aimed at developing an automatic facial expression interpreter, mainly in terms of emotions. The relevant findings on facial expressions from cognitive science and psychology that can be understood by and be useful to researchers in Human-Computer Interaction and Artificial Intelligence. From a philosophical perspective, technologies required to support knowledge transfer was categorized by two main cognitive processes: codification and interpretation (Garavelli, A.C.; Gorgoglione, M.; Scozzi, B. 2002).

A few studies were conducted regarding technical design factors of web sites. It was found that engineering design carried out by distributed design teams, in an effort to use expert human resources, operated more efficiently. In another technical design study, the support needs of distributed design were reviewed from a cognitive viewpoint using five broad categories: design methodology, collaboration, teamwork, knowledge management and design representation. Collaboration requires successful and efficient sharing of knowledge, negotiation, coordination and management of activities. In distributed environments, organizational factors and decisions that foster teamwork must be mediated by technology. Design intent, rationale and history are important basic types of knowledge that knowledge management systems are required to capture, organize and manipulate to help generate new design knowledge. The Lee study concluded that technology decision makers can identify the most relevant design factors and thereby allocate limited resources to them reasonably by performing the cognitive map simulation in advance before constructing design specification for electronic commerce sites (Lee K.C., Lee S., 2003). Efficient methods of representing design objects in different forms are needed that allow designers to interact most efficiently as well as support knowledge capture, transformation and collaborative activities (Lang, S.Y.T., Dickinson, J., Buchal, R.O. 2002).

Design has a major function in the ergonomic study of the human/technology relationship. It contains all of the psychological elements found in other behavioral phenomena, but has, a unique attribute, which is the need to transform principles and data from the behavioral domain to physical mechanisms that serve as behavioral surrogates. This requirement has both theoretical and practical consequences for human factors ergonomics (Meister 2000).

\section{Conclusion}

The scholarly field of human computer interaction is a growing field that does yet appear to have a grounded foothold. That being said, cognitive science certainly has influenced the applied science of HCI, 
specifically in economics, educational and new technologies. It would be difficult to argue these influences have had a dramatic impact on the practical field of HCI.

A review of the recent research provided evidence of contribution in economics, education and new technology. The economic research highlighted the lack of a cost benefit model and a lack of diversity in the IT field. Education HCI research needs a better foundation, but did discover students need technology training and test taking is not dramatically different on paper or a CRT. Technology research provided the most tangible results for applied science, with linguistic building robots and advances to be used by the handicap. All solid contribution to the applied science of HCI, but not staggering.

Despite the amazing advances in computing and HCI, humans will remain an integral part of current all tasks due to technical, economic, and cybernetics reasons (Mital, A. 1997).

\section{Resources}

[1] Amorim, Michel-Ange, Trumbore, Ben, Chogyen, Pema L. "Cognitive Repositioning inside a Desktop VE: The Constraints Introduced by First-versus Third-Person Imagery and Mental Representation Richness". Presence: Teleoperators\& Virtual Environments. 2000. Volume 9. Number 2. Pages: 165-186.

[2] Bazzini L. "From Grounding Metaphors to Technological Devices: A Call for Legitimacy in School Mathematics". Educational Studies in Mathematics. 2001. Volume 47. Number 3. Pages: 259-271.

[3] Boechler, Patricia M. "How Spatial Is Hyperspace? Interacting with Hypertext Cognitive Processes and Concepts". CyberPsychology\& Behavior. 2001. Volume 4. Number 1. Pages: 23-46

[4] Botelho, Luis Miguel, Coelho, Helder. "Machinery for Artificial Emotions."Cybernetics and Systems. 2001. Volume 32. Number 5. Pages: 465-506.

[5] Cacciabue P.C. "Human error risk management for engineering systems: a methodology for design, safety assessment, accident investigation and training". Reliability Engineering and System Safety.2004 Volume 83.Number 2. Pages: 229-240.

[6] Carroll, John M. "Becoming social: expanding scenario-based approaches in HCI". Behaviour and Information Technology. 1996. Volume 15. Number 4. Pages: $266-275$.

[7] Chalmers. P.A. " The role of cognitive theory in human-computer interface". Computers in Human Behavior. 2003. Volume 19. Number 5. Pages: 593-607.

[8] Clanchy, M.T. From Memory to Written Record: England, 1066-1307. Harvard University Press, 1979, rev. ed. 1991

[9] Coiera, E. "Interaction design theory". International Journal of Medical Informatics. 2003. Volume 69. Number 2. Pages: $205-222$

[10] Dautenhahn, Kerstin. "The Art of Designing Socially Intelligent Agents : Science, Fiction, and the Human in the Loop". Applied Artificial. 1998. Volume 12. Number 8. Pages: 573-617.

[11] De Miranda, Michael A. "The Grounding of a Discipline: Cognition and Instruction in Technology Education". International Journal of Technology and Design Education.

[12] 2004. Volume 14. Number 1. Pages: 61-77.

[13] Dobbyn, C, Stuart, S. “The Self as an Embedded Agent”. Minds and Machines.2003 Volume 13.Number 2. Pages: 187-201.

[14] Dowell, John, Long, John. “Target Paper”.Ergonomics. 1998. Volume 41. Number 2. Pages: 126 - 139.

[15] Fomichova, O., Fomichov V. "Computers and the thought-producing self of the young child". British Journal of Educational Technology. 2000. Volume 31. Number 3. Pages: 213-220.

[16] Garavelli, A.C.; Gorgoglione, M.; Scozzi, B. "Managing knowledge transfer by knowledge technologies.”Technovation. 2002. Volume 22. Number 5. Pages: 269-279.

[17] Garfield, Eugene, Pudovkin, A. I., Istomin, V. S. "Why do we need algorithmic historiography?" Journal of the American Society for Information Science and Technology.Volume 54.Issue 5. 2003. Pages: 400-412.

[18] Garland, Kate, Noyes, Jan. “CRT monitors: Do they interfere with learning?".Behaviour and Information Technology. 2003. Volume 23. Number 1. Pages: 43-52.

[19] Goldman, S.R., Zech L.K., Biswas G., Noser, T. "Computer technology and complex problem solving: Issues in the study of complex cognitive activity”. Instructional Science. 1999. Volume 27. Number 3. Pages: 235-268.

[20] Grassl, Richard M., Mingus Tabitha T. Y. "On the shoulders of technology: calculators as cognitive amplifiers". International Journal of Mathematical Education in Science and Technology. 2002. Volume 33. Number 5. Pages: 715-723.

[21] Hartson, Rex. "Cognitive, physical, sensory, and functional affordances in interaction design".Behaviour and Information Technology. 2003. Volume 22. Number 5. Pages: 315-338.

[22] Helander, M. G. "Forty years of IEA: some reflections on the evolution of ergonomics." Ergonomics. 1997. Volume 40. Number 10. Pages: $952-961$.

[23] Hoc, Jean-Michel.“From human-machine interaction to human-machine cooperation”.Ergonomics. 2000. Volume 43. Number 7. Page: $833-843$.

[24] Hollnagel, Erik. "Extended cognition and the future of ergonomics". Theoretical Issues in Ergonomics Science.2001 Volume 2.Number 3. Pages: 309-315.

[25] Irani Z., Sharif A., Love P.E.D., Kahraman C. "Applying concepts of fuzzy cognitive mapping to model: The IT/IS investment evaluation process". International Journal of Production Economics. 2002. Volume 75. Number 1. Pages: 199-211.

[26] Joia, Luiz Antonio. "Internet implementation in Brazilian K-12 schools".Internet Research. 1997. Volume 7. No. 4.

[27] Lang, S.Y.T., Dickinson, J., Buchal, R.O. “Cognitive factors in distributed design”. Computers in Industry. 2002. Volume 48. Number 1. Pages: 89-98.

[28] Law, Lai-Chong. "A situated cognition view about the effects of planning and authorship on computer program debugging". Behaviour and Information Technology. 1998. Volume 17. Number 6. Pages: 325-337.

[29] Lee K.C., Lee S., "A cognitive map simulation approach to adjusting the design factors of the electronic commerce web sites". Expert Systems with Applications. 2003. Volume 24. Number 1. Pages: 1-11.

[30] Lindsay, Martin. "Designing assessment tasks to accommodate students' cognitive skills in a technology-based mathematics course".International Journal of Mathematical Education. 1999. Volume 30. Number 5. Pages: 691-697.

[31] Lisetti, C.L., Schiano, D.J. "Automatic facial expression interpretation: Where human-computer interaction, artificial intelligence and cognitive science intersect”. Pragmatics \& Cognition. 2000. Volume 8. Number 1. Pages: 185-235.

[32] Lohse, Gerald L. "The role of working memory on graphical information processing". Behaviour and Information Technology. 1997. Volume 16. Number 6. Pages: 297-308 
[33] Long, J. "Specifying relations between research and the design of human-computer interactions." International Journal of HumanComputer Studies. 1996. Volume 44. Number 6. Pages: 875-920.

[34] Meister. David. "Cognitive processes in system design". Theoretical Issues in Ergonomics Science. 2000. Volume 1. Number 2. Pages: 113-138.

[35] Mital, A. "What role for humans in computer integrated manufacturing?". International Journal of Computer Integrated Manufacturing. 1997. Volume 10. Number 1. Pages: 190-198.

[36] Norman, E. “The Nature of Technology for Design”. International Journal of Technology and Design Education. 1998. Volume 8. Number 1. Pages: 67-87.

[37] Payne, Stephen J., Howes, Andrew, Reader, William R. "Adaptively distributing cognition: a decision-making perspective on human - computer interaction". Behaviour and Information Technology. 2001. Volume 20. Number 5. Pages: 339-346.

[38] Pfeifer, R. " Robots as cognitive tools". International Journal of Cognition and Technology. 2002. Volume 1. Number 1. Pages: $125-143$.

[39] Pollitzer E., Edmonds E., “ Editorial: the evolving partnership between cognitive science and HCI." International Journal of Human-Computer Studies. 1996. Volume 44. Number 6. Pages: 731-741.

[40] Rau, Pei-Luen P., Salvendy G., "Ergonomics guidelines for designing electronic mail addresses". Ergonomics. 2001. Number 4. Pages: 402-424.

[41] Riegler A. "When is a cognitive system embodied?" Cognitive Systems Research. Year 2002.Volume 3.Number 3. Pages: 339-348.

[42] Riva, Giuseppe. "The Mind Over the Web: The Quest for the Definition of a Method for Internet Research". CyberPsychology\& Behavior. 2001. Volume 4. Number 1. Pages: 7-16.

[43] Roco, M.C., Bainbridge, W.S. "Converging Technologies for Improving Human Performance: Integrating From the Nanoscale". Journal of Nanoparticle Research. 2002. Volume 4. Number 4. Pages: 281-295.

[44] Sandblad, Bengt, Gulliksen, Jan, Aborg, Carl, Boivie, Inger, Persson, Jenny, Goransson, Bengt, Kavathatzopoulos, Iordanis, Blomkvist, Stefan, Cajander, Asa. "Work environment and computer systems development". Behaviour and Information Technology. 2003. Volume 22. Number 6. Pages: 375-387.

[45] Saunders-Newton, D., Scott, H. "But the Computer Said!" Credible Uses of Computational Modeling in Public Sector Decision Making".Social Science Computer Review. 2001. Volume 19. Number 1. Pages: 47-65.

[46] Scheutz, M. “Computational versus Causal Complexity”.Minds and Machines. 2001. Volume 11. Number 4. Pages: $543-566$.

[47] Scaife, M.; Rogers Y. "External cognition: how do graphical representations work?" International Journal of Human-Computer Studies. 1996. Volume 45. Number 2. Pages: 185-213.

[48] Scott, Judy E. "Facilitating Interorganizational Learning with Information Technology".

[49] Journal of Management Information Systems. 2000. Volume 17. Number 2. Pages: 81-113.

[50] Schultheis, Maria T, Mourant, Ronald R. "Virtual Reality and Driving: The Road to Better Assessment for Cognitively Impaired Populations". Presence: Teleoperators\& Virtual Environments. 2001. Volume 10. Number 4. Pages: 431-439.

[51] Shaft, Teresa M. "Responses to comprehension questions and verbal protocols as measures of computer program comprehension processes".Behaviour and Information Technology.1997.Volume 16.Number 6. Pages: 320-336.

[52] Small, Henry. "Visualizing science by citation mapping."Journal of the American Society for Information Science. Volume 50, Issue 9. 1999. Pages: 799-813

[53] Smith, P.J. "Technology student learning preferences and the design of flexible learning programs". Instructional Science. 2001. Volume 29. Number 3. Pages: 237-254.

[54] Smith, Brooke; Caputi, Peter.“Cognitive interference in computer anxiety”.Behaviour and Information Technology. 2001. Volume 20. Number 4. Pages: 265-273.

[55] Stary, Chris, Peschl, Mark F. "Representation still matters: cognitive engineering and user interface design". Behaviour and Information Technology. 1998. Volume 17. Number 6. Pages: 338-360.

[56] Sumner, Tamara. "Promoting Scholarship Through Design". Information, Communication and Society. 2000. Volume 3. Number 4. Pages: 597-615.

[57] Sutcliffe A., Fickas S., Ehlhardt, M.M.S.A. "Investigating the usability of assistive user interfaces". Interacting with Computers. 2003. Volume 15. Number 4. Pages: 577-602.

[58] Trimmel, Michael, Raoul, Huber. "After-effects of human-computer interaction indicated by P300 of the event-related brain potential”.Ergonomics. 1998. Volume 41. Number 5. Pages: 649-655.

[59] Vogt, P. “The physical symbol-grounding problem.”Cognitive Systems Research. 2002. Volume 3. Number 3. Pages: $429-457$.

[60] Wang Y. " Cognitive Informatics: A New Transdisciplinary Research Field”. Brain and Mind. 2003. Volume 4. Number 2. Pages: $115-127$.

[61] White, Howard D., McCain Katherine W. "Visualizing a discipline: An author co-citation analysis of information science, 19721995."Journal of the American Society for Information Science. Volume 49.Issue 4. 1998. Pages: 327-355.

[62] Wilbon. A.D. "Shrinking the digital divide: the moderating role of technology environments". Technology in Society. 2003. Volume 25. Number 1. Pages: 83-97.

[63] Woods, David, Dekker, Sidney. "Anticipating the effects of technological change: a new era of dynamics for human factors". Theoretical Issues in Ergonomics Science. 2000. Volume 1. Number 3. Pages: 272-282.

[64] Yoon, Wan Chul. "The emergence of large-scale logical systems and cognitive ergonomics".Theoretical Issues in Ergonomics Science. 2001. Volume 2. Number 3. Pages: 251-267. 